\title{
Análise da viabilidade econômica do aproveitamento de água de chuva para edificações verticais do tipo residencial na Cidade de João Pessoa Estado da Paraíba
}

Analysis of the economic feasibility of using rainwater for vertical residential type buildings in the City of João Pessoa State of Paraíba

Análisis de la viabilidad económica del uso de agua de lluvia para edificios verticales de tipo residencial en la Ciudad de João Pessoa Estado de Paraíba

Recebido: 28/06/2021 | Revisado: 05/07/2021 | Aceito: 06/07/2021 | Publicado: 16/07/2021

\author{
Byanca Evelly dos Santos Martins \\ ORCID: https://orcid.org/0000-0001-6822-3946 \\ Universidade Federal da Paraíba, Brasil \\ E-mail: byancaevelly@gmail.com \\ Lenore Karla Medeiros Menezes \\ ORCID: https://orcid.org/0000-0003-2400-1094 \\ Universidade Federal da Paraíba, Brasil \\ E-mail: lenorekarla@hotmail.com \\ Cindy Deina Farto \\ ORCID: https://orcid.org/0000-0002-3092-092X \\ Universidade Federal da Paraíba, Brasil \\ E-mail: cindydeina2012@gmail.com \\ Gilson Barbosa Athayde Junior \\ ORCID: https://orcid.org/0000-0003-2815-7600 \\ Universidade Federal da Paraíba, Brasil \\ E-mail: gilson@ct.ufpb.br
}

\begin{abstract}
Resumo
O objetivo deste estudo é analisar a viabilidade econômica da implantação de um sistema de aproveitamento da água de chuva para atender a usos não potáveis em edificações verticais do tipo residencial na cidade de João Pessoa-PB, bem como avaliar a disposição da população da cidade em pagar um valor mais alto por um imóvel que possua esse sistema de captação de águas pluviais. A primeira hipótese considerou a variação no número de pavimentos, variando de 5 a 30. A segunda hipótese considerou a variação no volume do reservatório. Os volumes considerados e testados foram $15 \mathrm{~m}^{3}, 25 \mathrm{~m}^{3}, 45 \mathrm{~m}^{3}$ e $65 \mathrm{~m}^{3}$. Dessa forma, foram criados 104 cenários. Para verificar o interesse da população em sistemas de captação de água de chuva e a disposição em pagar a mais por esses sistemas, foi realizada uma pesquisa via formulários google, para cerca de 70 pessoas. Em 79,8\% dos cenários apresentaram B/C maior que 1. Para o reservatório de $15 \mathrm{~m}^{3}$, o que apresentou maior atratividade econômica, $92,31 \%$ dos cenários apresentaram $\mathrm{B} / \mathrm{C}$ maior que 1. O reservatório de $65 \mathrm{~m}^{3}$ apresentou apenas $65,38 \%$ dos valores do $\mathrm{B} / \mathrm{C}$ maior que 1 . O melhor desempenho atingido foi para o cenário de 21 pavimentos e reservatório de $15 \mathrm{~m}^{3}$, com o B/C de 1,96, VPL de R\$24.446,92 e período de retorno em 9,3 anos. A aplicação dos formulários revelou que $96,6 \%$ da população tem interesse em adquirir um imóvel com o sistema de aproveitamento e que $57,1 \%$ teriam disposição em pagar até $2 \%$ a mais do valor do imóvel.
\end{abstract}

Palavras-chave: Sistemas de aproveitamento de água da chuva; Análise econômica; Valor presente líquido; Relação benefício-custo.

\footnotetext{
Abstract

The objective of this study is to analyze the economic feasibility of implementing a rainwater catchment system to serve non-potable uses in vertical residential buildings in the city of João Pessoa, state of Paraíba, Brazil, and assess the willingness of the city's population to pay a higher price for a property that has this rainwater catchment system. The first hypothesis considers a variation in the number of floors, ranging from 5 to 30 . The second hypothesis considers a variation in the reservoir volume. The volumes considered and tested were $15 \mathrm{~m}^{3}, 25 \mathrm{~m}^{3}, 45 \mathrm{~m}^{3}$ and $65 \mathrm{~m}^{3}$. Thus, 104 scenarios were created. To verify the population's interest in rainwater harvesting systems and the willingness to pay extra for these systems, a survey was carried out via google forms, for about 70 people. Overall, $79.8 \%$ of the scenarios have $\mathrm{B} / \mathrm{C}$ greater than 1 . To the $15 \mathrm{~m}^{3}$ reservoir, which presented a greater economic attractiveness, $92.31 \%$ of the alternative scenarios B/C greater than 1 . The $65 \mathrm{~m}^{3}$ reservoir has only $65.38 \%$ of the B/C values greater than 1 . The best performance was achieved for the scenario of 21 floors and $15 \mathrm{~m}^{3}$ reservoir, with the $\mathrm{B} / \mathrm{C}$ of $1.96, \mathrm{NPV}$ of $\mathrm{R} \$ 24,446.92$ and payback period in 9.3 years. The application of the forms revealed that $96.6 \%$
} 
of the population is interested in acquiring a property with the development system and that $57.1 \%$ are willing to pay up to $2 \%$ more than the property's value.

Keywords: Rainwater harvesting systems; Economic analysis; Net present value; Cost-benefit ratio.

\section{Resumen}

El objetivo del estudio es analizar la viabilidad económica de implementar un sistema de captación de agua de lluvia para atender usos no potables en edificios residenciales verticales en la ciudad de João Pessoa-PB, así como evaluar la disposición de la población del ciudad a pagar un valor más alto por una propiedad que tiene este sistema de captación de agua de lluvia. La primera hipótesis consideró la variación en el número de pisos, que van de 5 a 30. La segunda hipótesis consideró la variación en el volumen del embalse. Los volúmenes considerados y ensayados fueron $15 \mathrm{~m}^{3}$, $25 \mathrm{~m}^{3}, 45 \mathrm{~m}^{3}$ y $65 \mathrm{~m}^{3}$. Así, se crearon 104 escenarios. Con el fin de verificar el interés de la población en los sistemas de captación de agua de lluvia y la voluntad de pagar extra por estos sistemas, se realizó una encuesta a través de formularios de Google, a unas 70 personas. El 79,8\% de los escenarios tiene B/C mayor a 1 . Al embalse de $15 \mathrm{~m}^{3}$, que presentó mayor atractivo económico, el 92,31\% de los escenarios tenía B/C mayor a 1 . El embalse de $65 \mathrm{~m}^{3}$ presentó solo el 65,38\% de los valores de B / C superiores a 1. El mejor desempeño alcanzado fue para el escenario con 21 pisos y un embalse de $15 \mathrm{~m}^{3}$, con un B / C de 1,96, un VPN de R \$24.446,92 y un período de recuperación de 9,3 años. La aplicación de los formularios reveló que el 96,6\% de la población está interesada en adquirir una propiedad con el sistema de desarrollo y que el $57,1 \%$ estaría dispuesto a pagar hasta un $2 \%$ más del valor de la propiedad.

Palabras clave: Sistemas de captación de agua de lluvia; Análisis economico; Valor presente neto; Relación beneficio-costo.

\section{Introdução}

Devido ao aumento da demanda por água no meio urbano, bem como em sistemas de geração de energia elétrica, a demanda mundial por esse recurso tem uma estimativa de aumento em 55\% até 2050, segundo o Relatório de Desenvolvimento Mundial da Água (World Water Assessment Programme, 2015). Além disso, as mudanças climáticas, a urbanização e a ausência de uma gestão hídrica adequada, aliadas ao uso não consciente da água, podem afetar o equilíbrio entre a oferta e a demanda de água potável, comprometendo assim, a disponibilidade hídrica em quantidade e qualidade suficientes para as gerações presentes e futuras (Jiménez Cisneros et al., 2014).

Dados do Relatório da Organização Mundial da Saúde estimam que uma em cada 10 pessoas (aproximadamente 785 milhões) não têm acesso à água potável e que se nada for feito até 2030, no sentido de preservar a água para fins mais nobres, o planeta vai sofrer com a falta d'água (World Health Organization, 2019).

Até mesmo no Brasil, país com grande oferta de água doce, os sinais da falta de acesso à água começam a aparecer nas regiões Norte e Nordeste. De acordo com o Sistema Nacional de Informações Sobre o Saneamento (SNIS), o índice total da população atendida com água é cerca 169,1 milhões (SNIS, 2018).

Cabe destacar que nas regiões Norte e Nordeste as causas da falta de água são distintas: enquanto a primeira carece de infraestrutura em relação aos sistemas de abastecimento de água, na segunda o problema é a baixa disponibilidade hídrica, sendo essa região conhecida por seus longos períodos de seca (Agência Nacional de Águas, 2019).

Diante dessa problemática da disponibilidade hídrica, aliada à dificuldade de se encontrar novas reservas, preocupações com o gerenciamento do uso da água ganham destaque e impulsionam pesquisas a buscarem fontes alternativas de captação deste recurso.

Inseridos nesse contexto, os sistemas de aproveitamento de água pluvial surgem como medidas que visam à conservação e redução de desperdícios da água e representam uma das alternativas contemporâneas de maior destaque no que se refere à sustentabilidade hídrica em áreas urbanas (Matos et al., 2013; Zhang \& Hu, 2014).

Esses sistemas de captação de água da chuva possibilitam a redução do consumo de água potável, poupando-se a utilização de uma água de boa qualidade que passou por diversos processos para chegar à potabilidade eproporcionam a minimização de enchentes/alagamentos em áreas urbanas (Salla et al., 2013; Kuchinski \& Gastaldini, 2017; Moura et al., 2018) 
e são uma das alternativas mais baratas, uma vez que não requerem tecnologias avançadas para sua implementação e operação (Mohammed et al., 2007).

De acordo com Maia et al. (2011), o uso das águas pluviais no meio urbano viabiliza a economia da água tratada proveniente do sistema convencional de abastecimento de água, uma vez que uma parcela da demanda de água doméstica, comercial, pública, ou mesmo de uso industrial, pode ser suprida por esse sistema.

A prática de captação de água da chuva, recentemente, tem sido usada em países com climas úmidos, principalmente com o interesse em aumentar as práticas de construção sustentável que apoiam o uso inteligente da água, especialmente para fins não potáveis (Cardoso et al. 2020). São exemplos de países que têm financiamento para a construção de sistemas de captação de águas pluviais: Austrália, África do Sul, Estados Unidos, Itália, Espanha e Portugal (Domènech \& Saurí, 2011; Ward et al., 2012; Thomas et al., 2014; Hajani \& Rahman, 2014; Silva et al., 2015; Ghimire et al., 2019).

No Brasil, embora a iniciativa de instalação desses sistemas não seja comumente praticada em edifícios públicos, comerciais e residenciais, o uso de a água da chuva já foi incorporado como um dos objetivos da Política Nacional de Recursos Hídricos, pela Lei 13.501 de 2017 (BRASIL, 2017). Infelizmente, a percepção dos benefícios do uso de águas pluviais em edificações no Brasil é pequena, pois as leis e incentivos são ainda recentes e insuficientes. De acordo com Pacheco et al., (2017), dos 26 estados e do Distrito Federal, apenas 7 estados possuem legislação para o uso da água da chuva, o que representa 26\%. Das 26 capitais, 16 possuem legislação referente a sistemas de captação de águas pluviais, o que corresponde a $62 \%$, contudo, a eficácia da aplicação da legislação é questionável devido à falta de políticas de incentivo.

Como a iniciativa do governo é recente, as ações e implementações de estudos relacionados a essa temática ainda são incipientes. Além disso, visto que a partir do século XXI ocorreu um aumento considerável na produção de edificações verticais para moradias, devido principalmente a diminuição de terrenos disponíveis nos centros urbanos, justifica-se a realização desse estudo como forma incentivar o uso de sistemas de captação de água de chuva no contexto de edifícios residenciais verticais, como parte integrante da gestão sustentável da água, além de apresentar dados de dimensionamento, que podem servir como parâmetro de referência para a legislações que se referem ao uso da água da chuva.

Nesse contexto, o objetivo do estudo é analisar a viabilidade econômica da implantação de um sistema de aproveitamento da água de chuva para atender a usos não potáveis em edificações verticais do tipo residencial na cidade de João Pessoa-PB, bem como avaliar a disposição da população da cidade em pagar um valor mais elevado por um imóvel que possua esse sistema de captação de águas pluviais.

\section{Metodologia}

A presente pesquisa apoia-se em um estudo de caso de uma edificação residencial do tipo vertical e multifamiliar, acoplada a uma pesquisa de campo para coleta de informações de custos acerca das instalações necessárias para implantação de sistemas de aproveitamento de água de chuva. É de cunho exploratório-descritivo (Gil, 2007) e do tipo quantitativa (Richardson, 2017).

\subsection{Caracterização do Empreendimento}

Para analisar a viabilidade econômica da implantação do sistema, um empreendimento localizado no bairro Jardim Oceania, cidade de João Pessoa-PB, foi utilizado como estudo de caso.

O empreendimento consiste em um residencial multifamiliar, com 10 pavimentos- tipo, 1 térreo e 1 subsolo de garagem, contendo 40 apartamentos, sendo 4 apartamentos por pavimento. Os apartamentos com terminação 01 e 04 possuem 1 cozinha, 2 salas, 2 banheiros, 3 quartos e 92,4m² e os apartamentos com terminação 02 e 03 possuem 1 varanda, 1 cozinha, 2 salas, 2 banheiros e 3 quartos e $91,46 \mathrm{~m}^{2}$. No térreo estão localizadas as áreas comuns do empreendimento, tais como piscina, 
áreas verdes, quadra, academia, espaço kids, home cinema, espaço gourmet, lobby, são de festa com cozinha, 2 banheiros e 1 lavabo.

O empreendimento é caracterizado como de médio/alto padrão, devido a localização e estrutura. O custo da obra aproximou-se de 10 milhões de reais. Visto que o valor de venda dos apartamentos variou de 450 mil reais a 500 mil reais, o valor venal chegou a aproximadamente 20 milhões de reais (Menezes, 2019).

\subsection{Cenários Hipotéticos}

Partindo das características do empreendimento do estudo de caso, foram criadas algumas hipóteses para posterior análise de cenários diversos, bem como análise da viabilidade econômica correspondente a cada cenário.

A primeira hipótese considera a variação no número de pavimentos, variando de 5 a 30 , contendo, em todos os casos, o térreo e pavimentos tipos, ambos com as mesmas características descritas no empreendimento base.

A segunda hipótese considera a variação no volume do reservatório. Os volumes considerados e testados foram $15 \mathrm{~m}^{3}$, $25 \mathrm{~m}^{3}, 45 \mathrm{~m}^{3}$ e $65 \mathrm{~m}^{3}$. Dessa forma, foram criados 104 cenários. É importante salientar que a precipitação se manteve fixa, assim como a área da coberta, já que a localização do empreendimento não muda em nenhum dos cenários analisados e o crescimento da edificação considerado é vertical.

\subsection{Oferta Pluviométrica}

Em estudos realizados por Andrade (2018), para caracterizar aspectos pluviométricos da cidade de João Pessoa, foi estudada uma série pluviométrica histórica de 35 anos (1983 - 2016), para o posto pluviométrico identificado pelo código 734006, localizado no bairro de Mandacaru. Os dados utilizados foram extraídos do Sistema Nacional de Informações sobre Recursos Hídricos (SNRIH), da Agência Nacional de Águas (ANA), no portal Hidroweb.

Na Figura 1 é possível observar a localização do posto pluviométrico utilizado para este estudo e a localização do empreendimento base. Utilizando o Google Earth, foi possível estimar uma distância em linha reta de 4,5 km entre o posto pluviométrico e o empreendimento base.

Figura 1 - Localização do posto pluviométrico e do empreendimento base.

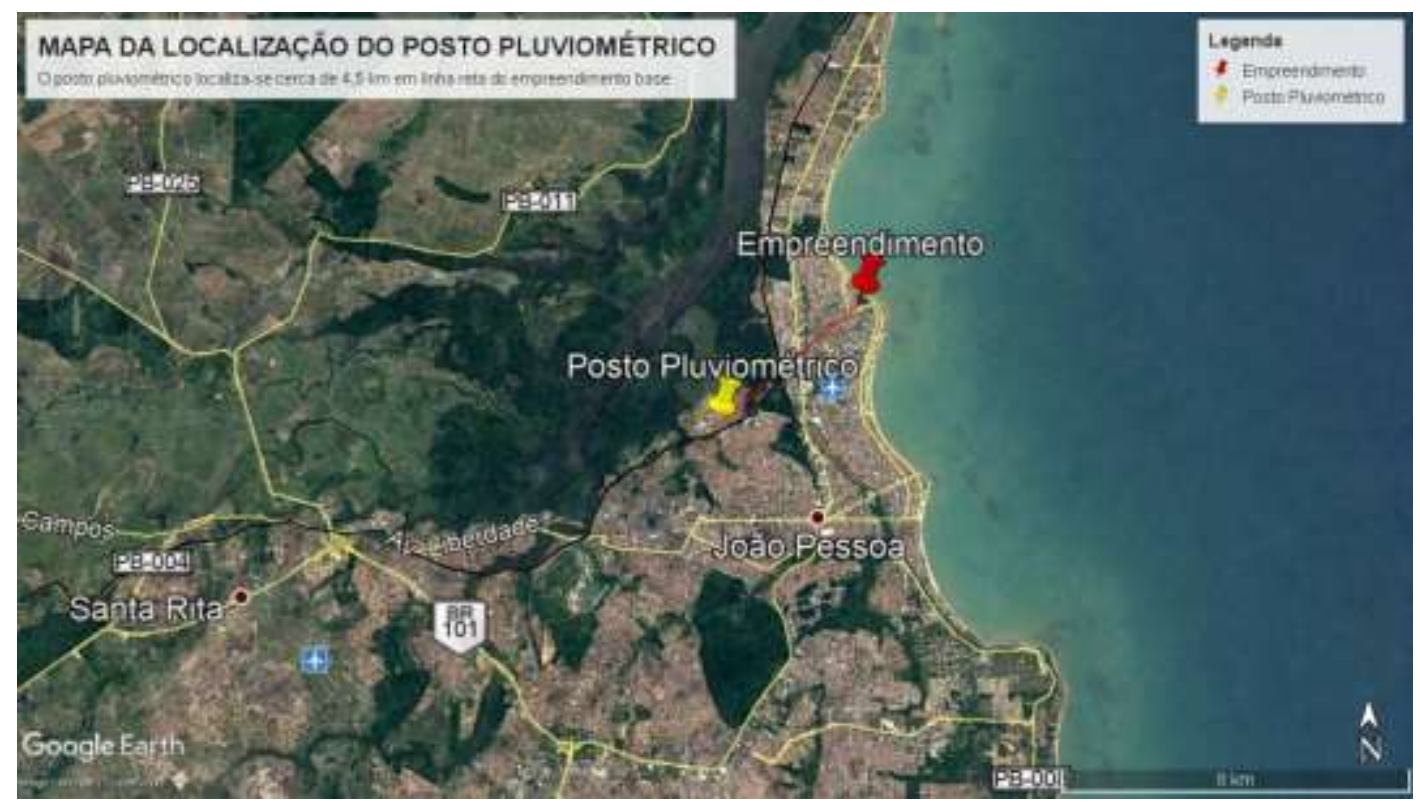

Fonte: Google Earth (2020). 
No tratamento desses dados, Andrade (2018) obteve uma média anual de 1.869,40 milímetros de chuva. O mês menos chuvoso é novembro, com precipitação média de $25 \mathrm{~mm}$ e o mês mais chuvoso é junho, com precipitação média de $354 \mathrm{~mm}$

A disponibilidade mensal de água está diretamente ligada a precipitação, área de captação e coeficiente de runoff. A área de captação é a mesma para todos os cenários, logo a disponibilidade mensal de água é independente da hipótese.

A área de captação do empreendimento é mista, composta por $370,89 \mathrm{~m}^{2}$ em telha de fibrocimento e $42,3 \mathrm{~m}^{2}$ em laje impermeabilizada, totalizando assim, 413,19 $\mathrm{m}^{2}$ (Figura 2). O coeficiente de runoff adotado corresponde ao valor de 0,81 , obtido por meio de uma média ponderada (Menezes, 2019).

Figura 2 - Área de captação.

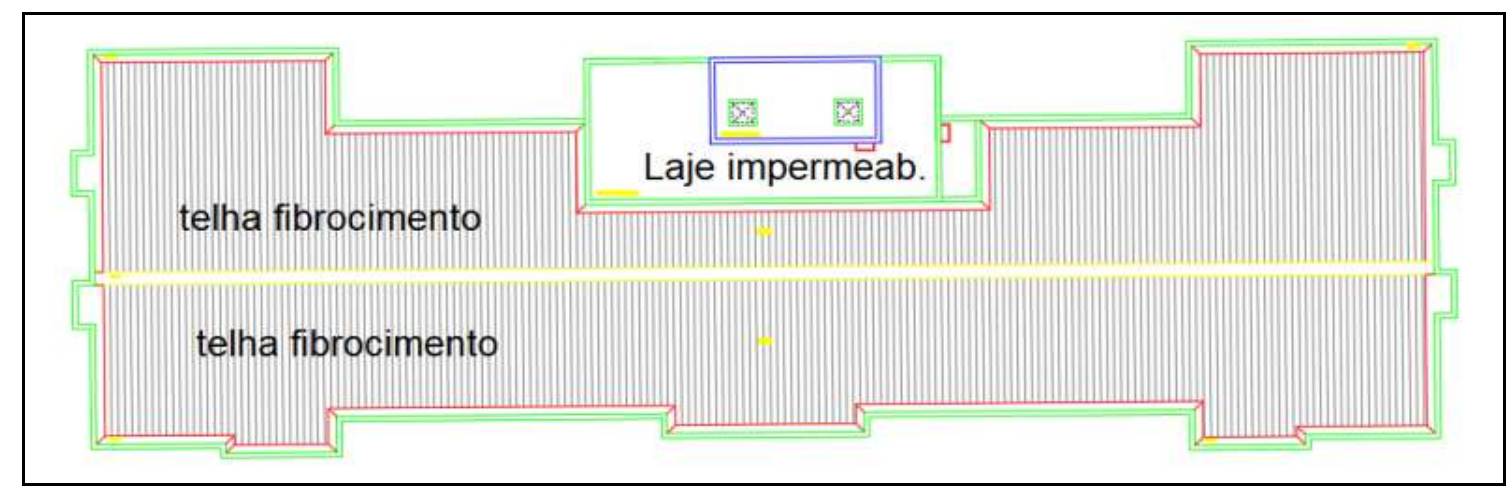

Fonte: Menezes (2019).

A fórmula geral, para o cálculo da disponibilidade de água mensal no empreendimento está expressa na Equação 1.

$$
V=P \cdot A \cdot C \quad \text { (Equação1) }
$$

Onde:

$\mathrm{V}=$ volume médio mensal de chuva apoveitado (1);

$\mathrm{P}=$ precipitação média mensal $(\mathrm{mm})$;

$\mathrm{A}=$ área de captação $\left(\mathrm{m}^{2}\right)$;

$\mathrm{C}=$ Coeficiente de escoamento superficial (runoff).

\subsection{Consumo de Água para Fins não Potáveis}

O consumo médio mensal necessário para atender as finalidades não potáveis corresponde a demanda de água não potável mensal de determinada população. No empreendimento em estudo, foi determinado que a demanda de água não potável será para atender as bacias sanitárias, quantificado assim, 4 banheiros de suítes por pavimento tipo a serem atendidas. Logo, o consumo médio variou de acordo com os cenários propostos.

Sabe-se que, no empreendimento em questão as bacias sanitárias possuem dois tipos de acionamentos, classificados como acionamento simples (3L/descarga) e acionamento duplo (6L/descarga). Posteriormente, foi identificado o consumo per capta e as bacias sanitárias que devem ser abastecidas. Dessa forma, a água utilizada para descarga das bacias sanitárias selecionadas deixa de ser comprada e fornecida pela concessionária de água e passa a ser fornecida pelo sistema de aproveitamento de água de chuva.

O consumo mensal de água não potável foi calculado através da Equação 2. 


$$
C m=n \cdot d \cdot D \quad \text { (Equação 2) }
$$

Onde:

$\mathrm{N}=$ população abastecida (hab);

$\mathrm{d}=$ Dias do mês (dia);

$\mathrm{D}=$ Demanda per capta por dia (1/hab.Dia).

\subsection{Dimensionamento do Reservatório de Armazenamento de Água da Chuva}

Todo o dimensionamento seguiu as recomendações da NBR 15527 (ABNT 2019), enquadrando-se dentro dos critérios técnicos e ambientais para posteriormente ser submetido a análise econômica.

O volume possível de ser captado e armazenado para cada variação de volume de reservatório foi analisado pelo método de Rippl. Além disso, outros volumes também foram analisados. Esses volumes foram escolhidos com base na disponibilidade pluviométrica, nas características do empreendimento e capacidade de captação da área da coberta. O armazenamento foi realizado parte em reservatório inferior e parte em reservatório superior.

O balanço volumétrico mensal usado para calcular o saldo mês a mês da reserva de água de chuva está expresso na Equação 3.

$$
S(t)=[O(t)-D(t)]+[S(t-10)] \quad(\text { Equação } 3)
$$

Onde:

$\mathrm{S}(\mathrm{t})=$ Volume de água no reservatório ao fim do mês corrente $(\mathrm{t})$;

$\mathrm{O}(\mathrm{t})=$ Volume de água ofertada para o mês corrente $(\mathrm{t})$;

$\mathrm{D}(\mathrm{t})=$ volume de água demandado para o mês corrente $(\mathrm{t})$;

$\mathrm{S}(\mathrm{t}-1)=$ Volume de água no reservatório remanescente do mês anterior ao mês corrente $(\mathrm{t})$.

\subsection{Tratamento}

Para o tratamento não foi considerado a utilização de soluções de químicas, já que o uso é não potável. Assim, optouse por um tratamento simplificado com filtro de areia, com o intuito de remover as partículas em suspensão na água que será armazenada.

A instalação do sistema de tratamento deve sempre ser feita antes da chegada da água ao reservatório. O filtro de areia foi dimensionado através da Equação 4.

$$
A_{f}=\frac{0,024 \cdot I \cdot A_{c}}{T_{f}} \text { (Equação 4) }
$$

Onde:

$A_{f}=$ Área do filtro $\left(\mathrm{m}^{2}\right)$;

$\mathrm{I}=$ Precipitação para duração de $5 \mathrm{~min}$ e tempo de recorrência de 5 anos;

$A_{c}=$ Área de contribuição do telhado $\left(\mathrm{m}^{2}\right)$;

$T_{f}=$ Taxa de filtração $\left(\mathrm{m}^{3} / \mathrm{m}^{2}\right.$.dia $)$. 


\subsection{Cálculo da Potência do Conjunto Motor-bomba}

Para os diferentes cenários foram exigidas diferentes potências de bombas. Quanto maior a altura manométrica, maior a potência do conjunto motor-bomba. Dessa forma, a potência solicitada variou de acordo com o número de pavimentos. Para o cálculo foi utilizada a Equação 5.

$$
P o t=\frac{\gamma \cdot Q_{R} \cdot H}{\eta} \quad(\text { Equação 5) }
$$

Onde:

Pot $=$ Potência $(\mathrm{w})$;

$\boldsymbol{\gamma}=$ Peso específico da água $\left(\mathrm{N} / \mathrm{m}^{3}\right)$;

$\mathrm{H}=$ Altura manométrica $(\mathrm{m})$;

$\eta=$ rendimento do conjunto motor-bomba;

$\mathrm{Q}_{\mathrm{r}}=\operatorname{vazão}\left(\mathrm{m}^{3} / \mathrm{s}\right)$.

\subsection{Análise Econômica}

\subsubsection{Custo de investimento direto $\eta$}

Os custos diretos foram baseados em Menezes (2019), com adaptações, atualizações e ressalvas. Os valores unitários dos itens foram atualizados para o ano de 2020. A instalação de calhas e tubulação de queda não foram incluídos, pois são instalados independentemente da existência do sistema de aproveitamento de água de chuva. Para os diversos cenários, verificou-se o acréscimo de material por andar para possibilitar a distribuição da água de aproveitamento e estimar o custo.

$\mathrm{O}$ filtro de areia foi idealizado com uma caixa de polietileno, pré-fabricada, $15 \mathrm{~m}^{3}$, além de uma camada de $1,14 \mathrm{~m}^{3}$ de brita, uma camada de bidin (manta geotêxtil) para separar as camadas, uma camada de areia média e $15 \mathrm{~m}$ de tubo de PVC 25MM, para fazer a ligação do sistema de tratamento até os reservatórios (Menezes, 2019).

A reservação foi pensada em caixas de polietileno e fibra de vidro, sendo o reservatório superior sempre com capacidade de $5 \mathrm{~m}^{3}$ e o reservatório inferior em caixas de $10 \mathrm{~m}^{3}$ ou $20 \mathrm{~m}^{3}$, com registos de gaveta para controle e manutenção do sistema e tubulações para sucção e recalque (Menezes, 2019).

A tubulação de recalque variou com a quantidade de pavimentos e houve um acréscimo de material para cada pavimento considerado, assim como o conjunto motor-bomba, que demandará uma potência maior quanto mais pavimentos houver no edifício.

Na distribuição, foi considerado a utilização de tubo de PVC 32MM para o barrilete até as colunas de distribuição, tubos de PVC 20MM para as colunas, ramais e sub-ramais. O sistema atende um banheiro por apartamento, ou seja, o sistema é composto por 4 colunas de distribuição (Menezes, 2019).

Os custos diretos foram levantados pelo software OrçaFascio, que é um site de orçamento de obras de construção civil, as bases orçamentárias usadas foram o SINAPI, valores referentes a maio de 2020 e ORSE, valores referentes a março de 2020 .

\subsubsection{Custo de investimento indireto}

O custo indireto considerado para o sistema de aproveitamento de água de chuva foi a depreciação por taxa de juros. Aplicou-se uma média histórica de 2 anos da taxa básica do Sistema Especial de Liquidação e Custódia, que é determina pelo Comitê de Política monetária do Banco Central. A Selic determina quanto os bancos vão pagar pelos títulos do governo, em 
consequência influência nas taxas para empréstimo de dinheiro para população, ou seja, a Selic influência nas taxas de juros do país.

A taxa básica de juros Selic, encontra-se em 2020 extremamente baixa, o que pode ser considerado um caso excepcional. De setembro de 2015 a setembro de 2016, a taxa Selic manteve-se em 14,15\%, quando começou a cair de forma gradual, até que em setembro de 2020 a taxa atingiu 1,9\%. Dessa forma, a série histórica considerada nesse trabalho foi a de Menezes (2019), que tem uma representação livre de anomalias.

\subsubsection{Custo de exploração}

O custo de exploração está relacionado com a manutenção do sistema. O mesmo foi avaliado por Menezes (2019) em 500 reais/ano.

\subsection{Benefício Econômico}

O benefício econômico é proporcionado pela redução do consumo de água da concessionária, em detrimento da utilização da água de chuva captada, por ano. O volume economizado por ano foi calculado para cada cenário possível e distribuído igualmente para o número de apartamentos correspondentes à cada cenário mês a mês, já que a cobrança do consumo de água é individual e mensal para cada apartamento.

Também foi determinado o consumo mensal regular para cada apartamento, partindo de um consumo per capita de 2001/dia. Além disso, foi consultada a estrutura tarifária da concessionária local. Considerando que a suíte comporta dois habitantes e os demais quartos um habitante, o consumo médio mensal global por apartamento é de aproximadamente $24 \mathrm{~m}^{3}$.

A economia máxima de água gerada pelo sistema de aproveitamento de água de chuva está diretamente ligada a economia da bacia sanitária da suíte, que foi calculada em $1,26 \mathrm{~m}^{3} / \mathrm{mês}$ por apartamento, consultando a estrutura tarifária da concessionária chegou-se à tarifa de $\mathrm{R} \$ 6,45 \mathrm{~m}^{3}$ de água, que corresponde a consumo mensal entre 21 e $30 \mathrm{~m}^{3}$.

Atualmente, a cobrança da taxa de água e de esgoto é relacionada ao consumo contabilizado pelo hidrômetro, mas, nesse trabalho, não foi levado em consideração o benefício na economia da taxa de esgoto, visto que a utilização do sistema de aproveitamento de água de chuva não reduz o lançamento de esgoto na rede da concessionária, logo existe a possibilidade de uma mudança na cobrança das tarifas.

Como parâmetros para análise econômica, utilizou-se o valor presente líquido (VPL), a relação benefício-custo (B/C) e o tempo de retorno capital (TRC), que são indicadores que relacionam os custos e os benefícios ao logo de determinado tempo, possibilitando assim, ser feita toda análise econômica dos sistemas de aproveitamento de água de chuva. O VPL foi calculado utilizando-se a Equação 6.

$$
V P L=\sum \frac{\text { Receita Líquida }}{\left(1+\frac{\text { Juros }}{100}\right)^{n}}-\text { Custos iniciais } \quad \text { (Equação 6) }
$$

Onde:

$\mathrm{VPL}=$ Benefício acumulado durante o horizonte de projeto;

Receita Líquida = Valor anual economizado;

Custos iniciais = Investimento para implantação do sistema;

Juros $=$ Taxa de juros anual $(6,42 \%$ a.a);

$\mathrm{N}=$ Horizonte de projeto (30 anos). 
Já a relação B/C é a razão entre o VPL acumulado e o investimento inicial. Se a relação B/C for maior que 1, então existe retorno econômico dentro do horizonte de projeto. Se a relação B/C for menor que 1, então não existe retorno econômico dentro do horizonte de projeto.

O TRC é obtido quando o VPL se torna maior que o custo inicial, alguns investimentos podem até mesmo nunca atingir um período de retorno, tendo em vista que o benefício decresce com o tempo, dessa forma quanto menor o período de retorno mais atrativo e seguro é o investimento.

\subsection{Disposição da População para Investir na Compra de Imóveis com Sistemas de Captação e Uso de Água de Chuva}

A fim de verificar o interesse da população de João Pessoa em sistemas de captação de água de chuva e a disposição em pagar a mais por esses sistemas, foi realizada uma pesquisa via formulários google, para cerca de 70 pessoas, que tenham comprado ou que estavam em busca de um imóvel na data da pesquisa.

\section{Resultados e Discussão}

\subsection{Oferta Pluviométrica}

Para determinação da oferta pluviométrica mensal foi utilizada a Equação 1, que relaciona a área de captação, precipitação média do local e o coeficiente de escoamento superficial. Dessa forma, como todas as variantes são fixas, o valor da oferta pluviométrica mensal foi calculado independentemente do cenário (Tabela 1).

Tabela 1 - Precipitação média na localidade e oferta pluviométrica mensal.

\begin{tabular}{ccc}
\hline Mês & $\begin{array}{c}\text { Precipitação } \\
(\mathbf{m m})\end{array}$ & $\begin{array}{c}\text { Oferta } \\
\left(\mathbf{m}^{3} / \mathbf{m e ̂ s}\right)\end{array}$ \\
\hline Janeiro & 82,87 & 27,74 \\
\hline Fevereiro & 104,77 & 35,06 \\
\hline Março & 188,06 & 62,94 \\
\hline Abril & 268,13 & 89,74 \\
\hline Maio & 280,65 & 93,93 \\
\hline Junho & 353,97 & 118,47 \\
\hline Julho & 285,27 & 95,48 \\
\hline Agosto & 153,45 & 51,36 \\
\hline Setembro & 75,39 & 25,23 \\
\hline Outubro & 32,56 & 10,90 \\
\hline Novembro & 25,04 & 8,38 \\
\hline Dezembro & 32,66 & 10,93 \\
\hline Soma & 1882,82 & 630,15 \\
\hline
\end{tabular}

Fonte: Martins (2020).

\subsection{Consumo de Água para fins não potáveis}

Para calcular o consumo médio mensal para fins não potáveis, foi definido que apenas a bacia sanitária do banheiro da suíte é abastecida com água de aproveitamento. Considerou-se que a suíte comporta 2 habitantes e que cada habitante faz uso de 5 acionamentos simples (3L/descarga) e 1 acionamento duplo (6L/descarga), dessa forma, a demanda diária por habitante corresponde a $21 \mathrm{~L}$.

Foi calculado através da Equação 2 o consumo médio mensal de água não potável, que varia com a hipótese de número de pavimentos, como pode ser visto na Tabela 2. 
Tabela 2 - Consumo médio mensal de água não potável.

\begin{tabular}{|c|c|c|c|c|c|c|c|c|c|}
\hline Pav. & 5 & 6 & 7 & 8 & 9 & 10 & 11 & 12 & 13 \\
\hline $\begin{array}{c}\text { Cm } \\
\left(\mathbf{m}^{3} / \mathbf{m e ̂ s}\right)\end{array}$ & 20,16 & 25,2 & 30,24 & 35,28 & 40,32 & 45,36 & 50,4 & 55,44 & 60,48 \\
\hline Pav. & 14 & 15 & 16 & 17 & 19 & 20 & 21 & 22 & 23 \\
\hline$\underset{\left(\mathbf{m}^{3} / \mathbf{m e ̂ s}\right)}{\mathrm{Cm}}$ & 65,52 & 70,56 & 75,6 & 80,64 & 90,72 & 95,76 & 100,8 & 105,84 & 110,88 \\
\hline Pav. & 24 & 25 & 26 & 27 & 28 & 29 & 30 & & \\
\hline$\underset{\left(\mathrm{m}^{3} / \mathrm{mês}\right)}{\mathrm{Cm}}$ & 115,92 & 120,96 & 126 & 131,04 & 136,08 & 141,12 & 146,16 & & \\
\hline
\end{tabular}

Fonte: Martins (2020).

\subsection{Reservatórios}

A princípio, analisou-se o volume do reservatório necessário para atender a demanda de todos os meses com saldo negativo em cada uma das hipóteses de número de pavimentos, o que corresponde ao método de Rippl. O volume necessário para 5 pavimentos foi $30,27 \mathrm{~m}^{3}$, o menor calculado e para 20 pavimentos foi $597,12 \mathrm{~m}^{3}$, o maior calculado. Nos demais pavimentos o saldo negativo calculado é maior que a oferta pluviométrica, não sendo então atrativo economicamente o método de Rippl. Dessa forma, aplicando a Equação 3, foi calculado o balanço mensal volumétrico apenas para os reservatórios de $15 \mathrm{~m}^{3}, 25 \mathrm{~m}^{3}, 45 \mathrm{~m}^{3}$ e $65 \mathrm{~m}^{3}$, combinados com cada um dos pavimentos propostos.

Em síntese, a Tabela 3 apresenta o panorama anual do somatório do balanço volumétrico mensal calculado para cada cenário estudado.

Tabela 3 - Panorama anual do aproveitamento de água de chuva.

\begin{tabular}{|c|c|c|c|c|c|c|}
\hline $\begin{array}{c}N^{0} \\
\text { de } \\
\text { pav. }\end{array}$ & $\begin{array}{l}\text { Vol. do } \\
\text { reservatório }\end{array}$ & $\begin{array}{c}\mathrm{V} \\
\text { demandado } \\
\left(\mathrm{m}^{3} / \mathbf{a n o}\right)\end{array}$ & $\begin{array}{c}\mathrm{V} \\
\text { aproveitado } \\
\left(\mathrm{m}^{3} / \mathbf{a n o}\right)\end{array}$ & $\begin{array}{c}\mathrm{V} \\
\text { extravasado } \\
\left(\mathbf{m}^{3} / \mathbf{a n o}\right)\end{array}$ & $\begin{array}{c}\% \text { de } \\
\text { aproveitamento } \\
\text { (ano) }\end{array}$ & $\begin{array}{c}\mathrm{V} \\
\underset{\left(\mathrm{m}^{3} / \mathrm{ano}\right)}{\operatorname{complementar}}\end{array}$ \\
\hline \multirow{4}{*}{$\begin{array}{c}5 \\
\text { PAV }\end{array}$} & $15 \mathrm{~m}^{3}$ & \multirow{4}{*}{241,92} & 226,65 & 403,50 & 93,69 & 15,27 \\
\hline & $25 \mathrm{~m}^{3}$ & & 236,65 & 393,50 & 97,82 & 5,27 \\
\hline & $45 \mathrm{~m}^{3}$ & & 256,65 & 373,50 & 100,00 & 0,00 \\
\hline & $65 \mathrm{~m}^{3}$ & & 276,65 & 353,50 & 100,00 & 0,00 \\
\hline \multirow{4}{*}{$\begin{array}{l}6 \\
\text { PAV }\end{array}$} & $15 \mathrm{~m}^{3}$ & \multirow{4}{*}{302,40} & 274,54 & 355,61 & 90,79 & 27,86 \\
\hline & $25 \mathrm{~m}^{3}$ & & 284,54 & 345,61 & 94,10 & 17,86 \\
\hline & $45 \mathrm{~m}^{3}$ & & 304,54 & 325,61 & 100,00 & 0,00 \\
\hline & $65 \mathrm{~m}^{3}$ & & 324,54 & 305,61 & 100,00 & 0,00 \\
\hline \multirow{4}{*}{$\begin{array}{c}7 \\
\text { PAV }\end{array}$} & $15 \mathrm{~m}^{3}$ & \multirow{4}{*}{362,88} & 309,86 & 320,29 & 85,39 & 53,02 \\
\hline & $25 \mathrm{~m}^{3}$ & & 319,86 & 310,29 & 88,14 & 43,02 \\
\hline & $45 \mathrm{~m}^{3}$ & & 339,86 & 290,29 & 93,66 & 23,02 \\
\hline & $65 \mathrm{~m}^{3}$ & & 359,86 & 270,29 & 99,17 & 3,02 \\
\hline \multirow{4}{*}{$\begin{array}{c}8 \\
\text { PAV }\end{array}$} & $15 \mathrm{~m}^{3}$ & \multirow{4}{*}{423,36} & 344,92 & 285,23 & 81,47 & 78,44 \\
\hline & $25 \mathrm{~m}^{3}$ & & 354,92 & 275,23 & 83,83 & 68,44 \\
\hline & $45 \mathrm{~m}^{3}$ & & 374,92 & 255,23 & 88,56 & 48,44 \\
\hline & $65 \mathrm{~m}^{3}$ & & 394,92 & 235,23 & 93,28 & 28,44 \\
\hline \multirow{4}{*}{$\begin{array}{c}9 \\
\text { PAV }\end{array}$} & $15 \mathrm{~m}^{3}$ & \multirow{4}{*}{483,84} & 375,16 & 254,99 & 77,54 & 108,68 \\
\hline & $25 \mathrm{~m}^{3}$ & & 385,16 & 244,99 & 79,61 & 98,68 \\
\hline & $45 \mathrm{~m}^{3}$ & & 405,16 & 224,99 & 83,74 & 78,68 \\
\hline & $65 \mathrm{~m}^{3}$ & & 425,16 & 204,99 & 87,87 & 58,68 \\
\hline \multirow{4}{*}{$\begin{array}{c}10 \\
\text { PAV }\end{array}$} & $15 \mathrm{~m}^{3}$ & \multirow{4}{*}{544,32} & 405,40 & 224,75 & 74,48 & 138,92 \\
\hline & $25 \mathrm{~m}^{3}$ & & 415,40 & 214,75 & 76,32 & 128,92 \\
\hline & $45 \mathrm{~m}^{3}$ & & 435,40 & 194,75 & 79,99 & 108,92 \\
\hline & $65 \mathrm{~m}^{3}$ & & 455,40 & 174,75 & 83,66 & 88,92 \\
\hline 11 & $15 \mathrm{~m}^{3}$ & 604,80 & 435,64 & 194,51 & 72,03 & 169,16 \\
\hline
\end{tabular}




\begin{tabular}{|c|c|c|c|c|c|c|}
\hline \multirow[t]{3}{*}{ PAV } & $25 \mathrm{~m}^{3}$ & & 445,64 & 184,51 & 73,68 & 159,16 \\
\hline & $45 m^{3}$ & & 465,64 & 164,51 & 76,99 & 139,16 \\
\hline & $65 \mathrm{~m}^{3}$ & & 485,64 & 144,51 & 80,30 & 119,16 \\
\hline \multirow{4}{*}{$\begin{array}{c}12 \\
\text { PAV }\end{array}$} & $15 \mathrm{~m}^{3}$ & \multirow{4}{*}{665,28} & 461,80 & 168,35 & 73,28 & 203,48 \\
\hline & $25 \mathrm{~m}^{3}$ & & 471,80 & 158,35 & 74,87 & 193,48 \\
\hline & $45 m^{3}$ & & 491,80 & 138,35 & 78,04 & 173,48 \\
\hline & $65 \mathrm{~m}^{3}$ & & 511,80 & 118,35 & 81,22 & 153,48 \\
\hline \multirow{4}{*}{$\begin{array}{c}13 \\
\text { PAV }\end{array}$} & $15 \mathrm{~m}^{3}$ & \multirow{4}{*}{725,76} & 487,00 & 143,15 & 77,28 & 238,76 \\
\hline & $25 \mathrm{~m}^{3}$ & & 497,00 & 133,15 & 78,87 & 228,76 \\
\hline & $45 \mathrm{~m}^{3}$ & & 517,00 & 113,15 & 82,04 & 208,76 \\
\hline & $65 \mathrm{~m}^{3}$ & & 537,00 & 93,15 & 85,22 & 188,76 \\
\hline \multirow{4}{*}{$\begin{array}{c}14 \\
\text { PAV }\end{array}$} & $15 \mathrm{~m}^{3}$ & \multirow{4}{*}{786,24} & 509,62 & 120,53 & 80,87 & 276,62 \\
\hline & $25 \mathrm{~m}^{3}$ & & 519,62 & 110,53 & 82,46 & 266,62 \\
\hline & $45 \mathrm{~m}^{3}$ & & 539,62 & 90,53 & 85,63 & 246,62 \\
\hline & $65 \mathrm{~m}^{3}$ & & 559,62 & 70,53 & 88,81 & 226,62 \\
\hline \multirow{4}{*}{$\begin{array}{c}15 \\
\text { PAV }\end{array}$} & $15 \mathrm{~m}^{3}$ & \multirow{4}{*}{846,72} & 529,78 & 100,37 & 84,07 & 316,94 \\
\hline & $25 \mathrm{~m}^{3}$ & & 539,78 & 90,37 & 85,66 & 306,94 \\
\hline & $45 \mathrm{~m}^{3}$ & & 559,78 & 70,37 & 88,83 & 286,94 \\
\hline & $65 \mathrm{~m}^{3}$ & & 579,78 & 50,37 & 92,01 & 266,94 \\
\hline \multirow{4}{*}{$\begin{array}{c}16 \\
\text { PAV }\end{array}$} & $15 \mathrm{~m}^{3}$ & \multirow{4}{*}{907,20} & 549,94 & 80,21 & 87,27 & 357,26 \\
\hline & $25 \mathrm{~m}^{3}$ & & 559,94 & 70,21 & 88,86 & 347,26 \\
\hline & $45 \mathrm{~m}^{3}$ & & 579,94 & 50,21 & 92,03 & 327,26 \\
\hline & $65 \mathrm{~m}^{3}$ & & 599,94 & 30,21 & 95,21 & 307,26 \\
\hline \multirow{4}{*}{$\begin{array}{c}17 \\
\text { PAV }\end{array}$} & $15 \mathrm{~m}^{3}$ & \multirow{4}{*}{967,68} & 570,10 & 60,05 & 90,47 & 397,58 \\
\hline & $25 \mathrm{~m}^{3}$ & & 580,10 & 50,05 & 92,06 & 387,58 \\
\hline & $45 \mathrm{~m}^{3}$ & & 600,10 & 30,05 & 95,23 & 367,58 \\
\hline & $65 \mathrm{~m}^{3}$ & & 620,10 & 10,05 & 98,40 & 347,58 \\
\hline \multirow{4}{*}{$\begin{array}{c}18 \\
\text { PAV }\end{array}$} & $15 \mathrm{~m}^{3}$ & \multirow{4}{*}{1028,16} & 590,26 & 39,89 & 93,67 & 437,90 \\
\hline & $25 \mathrm{~m}^{3}$ & & 600,26 & 29,89 & 95,26 & 427,90 \\
\hline & $45 \mathrm{~m}^{3}$ & & 620,26 & 9,89 & 98,43 & 407,90 \\
\hline & $65 \mathrm{~m}^{3}$ & & 630,15 & 0,00 & 100,00 & 398,01 \\
\hline \multirow{4}{*}{$\begin{array}{c}19 \\
\text { PAV }\end{array}$} & $15 \mathrm{~m}^{3}$ & \multirow{4}{*}{1088,64} & 609,44 & 20,71 & 96,71 & 479,20 \\
\hline & $25 \mathrm{~m}^{3}$ & & 619,44 & 10,71 & 98,30 & 469,20 \\
\hline & $45 \mathrm{~m}^{3}$ & & 630,15 & 0,00 & 100,00 & 458,49 \\
\hline & $65 \mathrm{~m}^{3}$ & & 630,15 & 0,00 & 100,00 & 458,49 \\
\hline \multirow{4}{*}{$\begin{array}{c}20 \\
\text { PAV }\end{array}$} & $15 \mathrm{~m}^{3}$ & & 622,44 & 7,71 & 98,78 & 526,68 \\
\hline & $25 \mathrm{~m}^{3}$ & 114912 & 630,15 & 0,00 & 100,00 & 518,97 \\
\hline & $45 \mathrm{~m}^{3}$ & 1149,12 & 630,15 & 0,00 & 100,00 & 518,97 \\
\hline & $65 \mathrm{~m}^{3}$ & & 630,15 & 0,00 & 100,00 & 518,97 \\
\hline & $15 \mathrm{~m}^{3}$ & & 630,15 & 0,00 & 100,00 & 579,45 \\
\hline 21 & $25 \mathrm{~m}^{3}$ & 120060 & 630,15 & 0,00 & 100,00 & 579,45 \\
\hline PAV & $45 \mathrm{~m}^{3}$ & 1200,00 & 630,15 & 0,00 & 100,00 & 579,45 \\
\hline & $65 \mathrm{~m}^{3}$ & & 630,15 & 0,00 & 100,00 & 579,45 \\
\hline & $15 \mathrm{~m}^{3}$ & & 630,15 & 0,00 & 100,00 & 639,93 \\
\hline 22 & $25 \mathrm{~m}^{3}$ & 107008 & 630,15 & 0,00 & 100,00 & 639,93 \\
\hline PAV & $45 \mathrm{~m}^{3}$ & $12 / 0,00$ & 630,15 & 0,00 & 100,00 & 639,93 \\
\hline & $65 \mathrm{~m}^{3}$ & & 630,15 & 0,00 & 100,00 & 639,93 \\
\hline & $15 \mathrm{~m}^{3}$ & & 630,15 & 0,00 & 100,00 & 700,41 \\
\hline 23 & $25 \mathrm{~m}^{3}$ & 133056 & 630,15 & 0,00 & 100,00 & 700,41 \\
\hline PAV & $45 m^{3}$ & טכ,ענכון & 630,15 & 0,00 & 100,00 & 700,41 \\
\hline & $65 \mathrm{~m}^{3}$ & & 630,15 & 0,00 & 100,00 & 700,41 \\
\hline & $15 \mathrm{~m}^{3}$ & & 630,15 & 0,00 & 100,00 & 760,89 \\
\hline 24 & $25 \mathrm{~m}^{3}$ & 139104 & 630,15 & 0,00 & 100,00 & 760,89 \\
\hline PAV & $45 \mathrm{~m}^{3}$ & (15) & 630,15 & 0,00 & 100,00 & 760,89 \\
\hline & $65 \mathrm{~m}^{3}$ & & 630,15 & 0,00 & 100,00 & 760,89 \\
\hline 25 & $15 \mathrm{~m}^{3}$ & 1451,52 & 630,15 & 0,00 & 100,00 & 821,37 \\
\hline
\end{tabular}




\begin{tabular}{|c|c|c|c|c|c|c|}
\hline \multirow[t]{3}{*}{ PAV } & $25 \mathrm{~m}^{3}$ & & 630,15 & 0,00 & 100,00 & 821,37 \\
\hline & $45 m^{3}$ & & 630,15 & 0,00 & 100,00 & 821,37 \\
\hline & $65 \mathrm{~m}^{3}$ & & 630,15 & 0,00 & 100,00 & 821,37 \\
\hline \multirow{4}{*}{$\begin{array}{c}26 \\
\text { PAV }\end{array}$} & $15 \mathrm{~m}^{3}$ & \multirow{4}{*}{1512,00} & 630,15 & 0,00 & 100,00 & 881,85 \\
\hline & $25 \mathrm{~m}^{3}$ & & 630,15 & 0,00 & 100,00 & 881,85 \\
\hline & $45 \mathrm{~m}^{3}$ & & 630,15 & 0,00 & 100,00 & 881,85 \\
\hline & $65 \mathrm{~m}^{3}$ & & 630,15 & 0,00 & 100,00 & 881,85 \\
\hline \multirow{4}{*}{$\begin{array}{c}27 \\
\text { PAV }\end{array}$} & $15 \mathrm{~m}^{3}$ & \multirow{4}{*}{1572,48} & 630,15 & 0,00 & 100,00 & 942,33 \\
\hline & $25 \mathrm{~m}^{3}$ & & 630,15 & 0,00 & 100,00 & 942,33 \\
\hline & $45 \mathrm{~m}^{3}$ & & 630,15 & 0,00 & 100,00 & 942,33 \\
\hline & $65 \mathrm{~m}^{3}$ & & 630,15 & 0,00 & 100,00 & 942,33 \\
\hline \multirow{4}{*}{$\begin{array}{c}28 \\
\text { PAV }\end{array}$} & $15 \mathrm{~m}^{3}$ & \multirow{4}{*}{1632,96} & 630,15 & 0,00 & 100,00 & 1002,81 \\
\hline & $25 \mathrm{~m}^{3}$ & & 630,15 & 0,00 & 100,00 & 1002,81 \\
\hline & $45 m^{3}$ & & 630,15 & 0,00 & 100,00 & 1002,81 \\
\hline & $65 \mathrm{~m}^{3}$ & & 630,15 & 0,00 & 100,00 & 1002,81 \\
\hline \multirow{4}{*}{$\begin{array}{c}29 \\
\text { PAV }\end{array}$} & $15 \mathrm{~m}^{3}$ & \multirow{4}{*}{1693,44} & 630,15 & 0,00 & 100,00 & 1063,29 \\
\hline & $25 \mathrm{~m}^{3}$ & & 630,15 & 0,00 & 100,00 & 1063,29 \\
\hline & $45 \mathrm{~m}^{3}$ & & 630,15 & 0,00 & 100,00 & 1063,29 \\
\hline & $65 \mathrm{~m}^{3}$ & & 630,15 & 0,00 & 100,00 & 1063,29 \\
\hline \multirow{4}{*}{$\begin{array}{c}\text { 30 } \\
\text { PAV }\end{array}$} & $15 \mathrm{~m}^{3}$ & \multirow{4}{*}{1753,92} & 630,15 & 0,00 & 100,00 & 1123,77 \\
\hline & $25 \mathrm{~m}^{3}$ & & 630,15 & 0,00 & 100,00 & 1123,77 \\
\hline & $45 \mathrm{~m}^{3}$ & & 630,15 & 0,00 & 100,00 & 1123,77 \\
\hline & $65 \mathrm{~m}^{3}$ & & 630,15 & 0,00 & 100,00 & 1123,77 \\
\hline
\end{tabular}

Fonte: Martins (2020).

De acordo com a Tabela 3, os cenários em que não foram necessários adquirir água complementarmente da concessionária foram o de 5 e 6 pavimentos com reservatório de $45 \mathrm{~m}^{3}$ e $65 \mathrm{~m}^{3}$. Logo, o percentual de aproveitamento da água de chuva captada é máximo. Também se obteve aproveitamento máximo em qualquer reservatório a partir do pavimento 21. Contudo, o volume completar não é zero, pois nesses casos o consumo médio anual é muito grande, chegando a ser superior a oferta pluviométrica.

\subsection{Tratamento}

Tem-se por definição que a área do filtro de areia está relacionada com a precipitação de duração de 5 min e tempo de retorno de 5 anos, área de contribuição e taxa de filtração, logo, para todos os cenários estudados, o filtro de areia dimensionado possui a mesma área.

Para o cálculo foi considerado uma camada de brita com $20 \mathrm{~cm}$ e uma camada filtrante simples com $60 \mathrm{~cm}$ de fluxo descendente, taxa de filtração de $180 \mathrm{~m}^{3} / \mathrm{m}^{2}$.dia e para a precipitação de duração de $5 \mathrm{~min}$ e tempo de retorno de 5 anos, 140mm/h (Menezes, 2019). Dessa maneira, conforme a Equação 4, a área calculada do filtro de areia foi de 7,71 $\mathrm{m}^{2}$.

\subsection{Cálculo da Potência do Conjunto Motor-Bomba}

Na determinação do conjunto motor-bomba foi aplicada a Equação 5. Como a potência requerida aumenta com a vazão e altura manométrica, tem-se uma potência calculada para cada pavimento. Considerando para cálculo, o rendimento de $50 \%$ e o peso específico da água em $9790,4 \mathrm{~N} / \mathrm{m}^{3}$, obteve-se a potência comercial de $1 / 3 \mathrm{CV}$ para o pavimento 5 ao $23,1 / 2 \mathrm{CV}$ para o pavimento 24 ao 28 e $3 / 4 \mathrm{CV}$ para o pavimento 29 e 30. 


\subsection{Benefício e Custo}

\subsubsection{Filtro de areia}

O custo de cada item do filtro de areai foi levantado nas bases orçamentários SINAPI e ORSE, totalizando $\mathrm{R} \$ 8.339,88$. Esse custo inclui a ligação do filtro de areia ao sistema de armazenamento e toda a estrutura de tratamento da água de aproveitamento de chuva (Tabela 4).

Tabela 4 - Orçamento para execução do filtro de areia.

\begin{tabular}{|c|c|c|c|c|c|c|}
\hline \multirow{3}{*}{$\begin{array}{c}\text { Item } \\
1 \\
\end{array}$} & \multicolumn{2}{|r|}{ Descriminação } & \multirow[t]{3}{*}{ Und } & \multirow[t]{3}{*}{ Quant. } & \multicolumn{2}{|c|}{ Preço (r\$) } \\
\hline & & & & & Unit. & Total \\
\hline & \multicolumn{2}{|r|}{ Filtro de areia } & & & & \\
\hline 1.1 & $\begin{array}{l}\text { 00202/ } \\
\text { ORSE }\end{array}$ & $\begin{array}{l}\text { Areia média, adquirida em depósito, } \\
\text { frete incluso (areia média comercial) }\end{array}$ & $\mathrm{M}^{3}$ & 6,00 & 63,64 & 381,84 \\
\hline 1.2 & $\begin{array}{l}10929 / \\
\text { ORSE }\end{array}$ & Brita 1 (9,5 à 19MM) - incluso o frete & $\mathrm{M}^{3}$ & 1,14 & 70,02 & 79,47 \\
\hline 1.3 & $\begin{array}{l}\text { 00465/ } \\
\text { ORSE }\end{array}$ & $\begin{array}{l}\text { Caixa d'água de fibra de vidro } 15.000 \\
\text { litros - Fortlev-torres (ou similar) }\end{array}$ & UN & 1,00 & 7439,88 & 7439,88 \\
\hline 1.4 & $\begin{array}{l}91785 / \\
\text { SINAPI }\end{array}$ & $\begin{array}{l}\text { (Composição representativa) do serviço } \\
\text { de instalação de tubos de PVC, série R, } \\
\text { água pluvial, DN } 25 \mathrm{MM} \text { (instalado em } \\
\text { ramal de encaminhamento, ou } \\
\text { condutores verticais), inclusive } \\
\text { conexões, corte e fixações, para } \\
\text { prédios. AF } 10 / 2015\end{array}$ & M & 15,00 & 27,15 & 407,25 \\
\hline 1.5 & $\begin{array}{c}01586 \\
\text { /ORSE }\end{array}$ & $\begin{array}{l}\text { Manta geotêxtil não tecido RT-10, } \\
\text { resistência a tração= } 10 \mathrm{KN} / \mathrm{M} \text { (antigo } \\
\text { bidim op- } 20 \text { ou similar) }\end{array}$ & $\mathrm{M}^{2}$ & 6,00 & 5,24 & 31,44 \\
\hline
\end{tabular}

\section{TOTAL}

$\mathbf{R} \$ \mathbf{8 . 3 3 9 , 8 8}$

Fonte: Martins (2020).

\subsubsection{Reservatórios}

Para cada cenário variou o custo do sistema de reservação em função da tubulação de recalque, potência do conjunto motor-bomba e a capacidade de armazenamento de água de chuva. O custo inclui o reservatório inferior e superior, além toda a instalação hidráulica, entre eles, os itens desse orçamento foram levantados nas bases orçamentários SINAPI e ORSE. Na Tabela 5, o custo do sistema de reservação para cada um dos cenários. 
Tabela 5 - Custo do sistema de reservação para cada cenário.

\begin{tabular}{|c|c|c|c|c|c|c|}
\hline \multirow[t]{2}{*}{ PAV. } & \multirow{2}{*}{$\begin{array}{l}\text { Potência } \\
\text { do CJ. } \\
\text { Motor- } \\
\text { bomba } \\
\text { (CV) }\end{array}$} & \multirow{2}{*}{$\begin{array}{l}\text { Tubulação } \\
\text { de } \\
\text { recalque } \\
\text { (m) }\end{array}$} & \multicolumn{4}{|c|}{$\begin{array}{l}\text { Custo do sistema de reservação } \\
(\mathrm{R} \$)\end{array}$} \\
\hline & & & $15 \mathrm{~m}^{2}$ & $25 \mathrm{~m}^{3}$ & $45 \mathrm{~m}^{3}$ & $65 \mathrm{~m}^{3}$ \\
\hline 5 & $1 / 3$ & 21,06 & 7934,17 & 12118,63 & 19807,627 & 27496,627 \\
\hline 6 & $1 / 3$ & 23,85 & 8016,78 & 12201,24 & 19890,237 & 27579,237 \\
\hline 7 & $1 / 3$ & 26,64 & 8099,39 & 12283,85 & 19972,847 & 27661,847 \\
\hline 8 & $1 / 3$ & 29,43 & 8182 & 12366,46 & 20055,457 & 27744,457 \\
\hline 9 & $1 / 3$ & 32,22 & 8264,61 & 12449,07 & 20138,067 & 27827,067 \\
\hline 10 & $1 / 3$ & 35,01 & 8347,22 & 12531,68 & 20220,677 & 27909,677 \\
\hline 11 & $1 / 3$ & 37,8 & 8429,83 & 12614,29 & 20303,287 & 27992,287 \\
\hline 12 & $1 / 3$ & 40,59 & 8512,44 & 12696,9 & 20385,897 & 28074,897 \\
\hline 13 & $1 / 3$ & 43,38 & 8595,05 & 12779,51 & 20468,507 & 28157,507 \\
\hline 14 & $1 / 3$ & 46,17 & 8677,66 & 12862,12 & 20551,117 & 28240,117 \\
\hline 15 & $1 / 3$ & 48,96 & 8760,27 & 12944,73 & 20633,727 & 28322,727 \\
\hline 16 & $1 / 3$ & 51,75 & 8842,88 & 13027,34 & 20716,337 & 28405,337 \\
\hline 17 & $1 / 3$ & 54,54 & 8925,49 & 13109,95 & 20798,947 & 28487,947 \\
\hline 18 & $1 / 3$ & 57,33 & 9008,1 & 13192,56 & 20881,557 & 28570,557 \\
\hline 19 & $1 / 3$ & 60,12 & 9090,71 & 13275,17 & 20964,167 & 28653,167 \\
\hline 20 & $1 / 3$ & 62,91 & 9173,32 & 13357,78 & 21046,777 & 28735,777 \\
\hline 21 & $1 / 3$ & 65,7 & 9255,93 & 13440,39 & 21129,387 & 28818,387 \\
\hline 22 & $1 / 3$ & 68,49 & 9338,54 & 13523 & 21211,997 & 28900,997 \\
\hline 23 & $1 / 3$ & 71,28 & 9421,15 & 13605,61 & 21294,607 & 28983,607 \\
\hline 24 & $1 / 2$ & 74,07 & 9528,08 & 13712,54 & 21401,543 & 29090,543 \\
\hline 25 & $1 / 2$ & 76,86 & 9610,69 & 13795,15 & 21484,153 & 29173,153 \\
\hline 26 & $1 / 2$ & 79,65 & 9693,3 & 13877,76 & 21566,763 & 29255,763 \\
\hline 27 & $1 / 2$ & 82,44 & 9775,91 & 13960,37 & 21649,373 & 29338,373 \\
\hline 28 & $1 / 2$ & 85,23 & 9858,52 & 14042,98 & 21731,983 & 29420,983 \\
\hline 29 & $3 / 4$ & 88,02 & 9858,53 & 14549,76 & 21814,593 & 29927,762 \\
\hline 30 & $3 / 4$ & 90,81 & 9941,14 & 14632,37 & 21897,203 & 30010,372 \\
\hline
\end{tabular}

Fonte: Martins (2020).

\subsubsection{Distribuição}

O custo da distribuição foi levantado nas bases orçamentários SINAPI e ORSE, e varia com a hipótese de número de pavimentos. O custo da distribuição inclui toda instalação que leva a água de aproveitamento do sistema de reservação ao ponto contemplado. Na Tabela 6, o custo do sistema de distribuição para cada um dos pavimentos considerados. 
Tabela 6 - Custo do sistema distribuição para cada cenário.

\begin{tabular}{cccc}
\hline Pavimentos & $\begin{array}{c}\text { Custo da distribuição } \\
\text { (R\$) }\end{array}$ & Pavimentos & $\begin{array}{c}\text { Custo da distribuição } \\
\text { (R\$) }\end{array}$ \\
\hline $\mathbf{5}$ & $4.706,02$ & 18 & $8.969,91$ \\
$\mathbf{6}$ & $5.034,01$ & 19 & $9.297,90$ \\
$\mathbf{7}$ & $5.362,00$ & 20 & $9.625,90$ \\
$\mathbf{8}$ & $5.689,99$ & 21 & $9.953,89$ \\
$\mathbf{9}$ & $6.017,99$ & 22 & $10.281,88$ \\
$\mathbf{1 0}$ & $6.345,98$ & 23 & $10.609,87$ \\
$\mathbf{1 1}$ & $6.673,97$ & 24 & $10.937,86$ \\
$\mathbf{1 2}$ & $7.001,96$ & 25 & $11.265,86$ \\
$\mathbf{1 3}$ & $7.329,95$ & 26 & $11.593,85$ \\
$\mathbf{1 4}$ & $7.657,95$ & 27 & $11.921,84$ \\
$\mathbf{1 5}$ & $7.985,94$ & 28 & $12.249,83$ \\
$\mathbf{1 6}$ & $7.985,94$ & 29 & $12.577,82$ \\
$\mathbf{1 7}$ & $8.641,92$ & 30 & $12.905,81$ \\
\hline
\end{tabular}

Fonte: Martins (2020).

\subsection{Benefício para o consumidor}

Os sistemas de aproveitamento de água de chuva propostos foram analisados para um horizonte de projeto de 30 anos, taxa de juros $6,42 \%$ ao ano e tarifa de água de $6,45 \mathrm{R} \$ / \mathrm{m}^{3}$. Como já exposto, o sistema de aproveitamento foi secionado em 3 partes, sendo elas: tratamento (filtro de areia), reservação e distribuição. Os custos relacionados aos itens que compõem o sistema de aproveitamento de água de chuva são sensíveis às hipóteses levantadas, logo, cada cenário apresenta um custo inicial individual para instalação do sistema de aproveitamento de água de chuva, que corresponde a soma do sistema de tratamento, reservação e distribuição.

Em posse dos custos iniciais, das receitas líquidas e utilizando a Equação 6, calculou-se o VPL (Figura 3), o B/C (Figura 4) e o TRC (Figura 5) para cada cenário.

Figura 1 - VPL por pavimento.

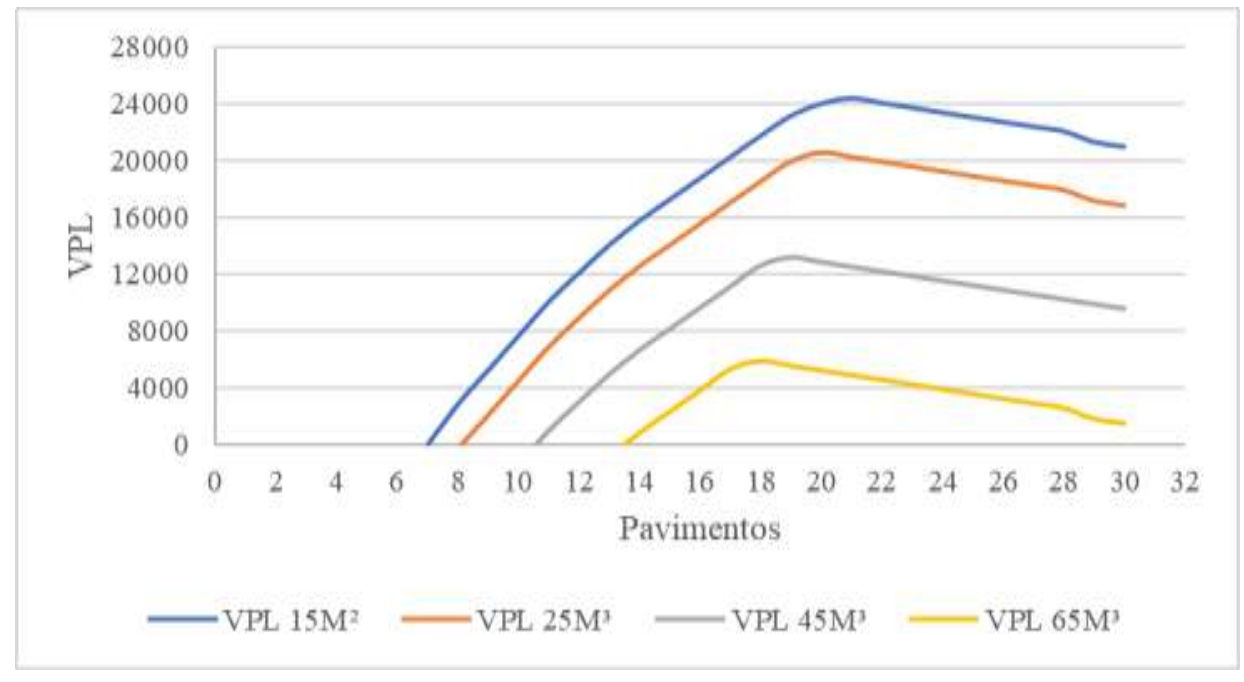

Fonte: Martins (2020). 


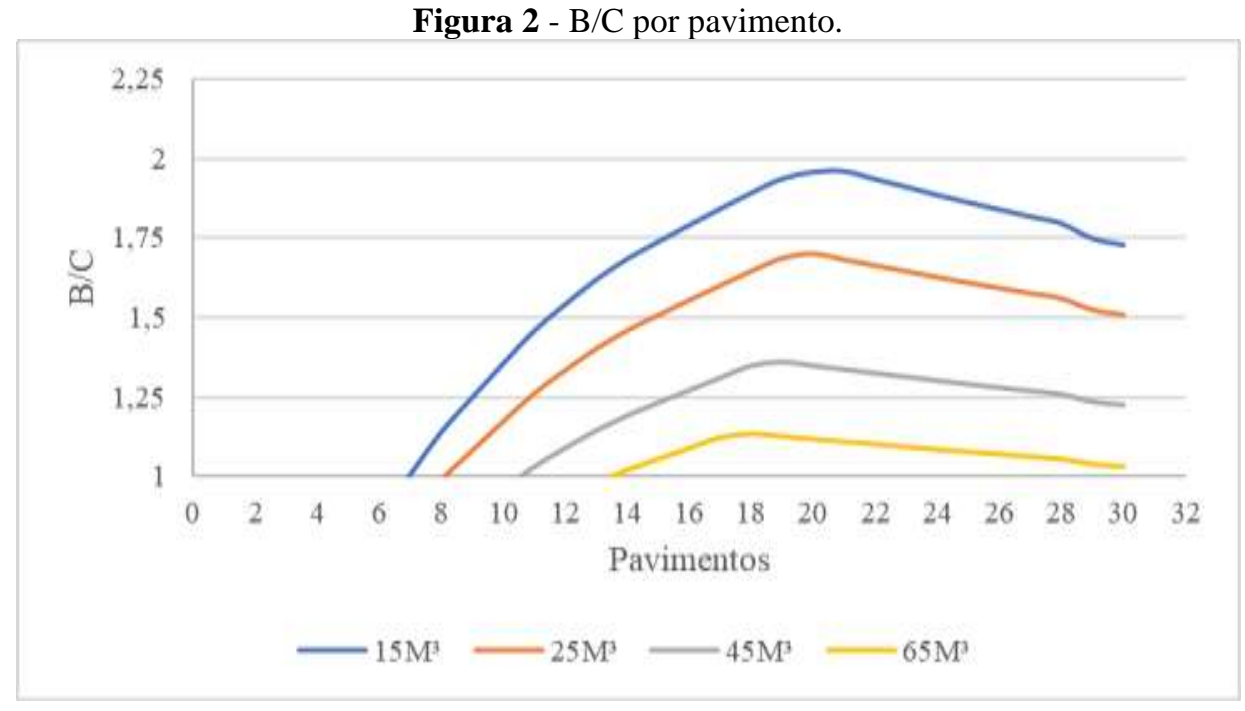

Fonte: Martins (2020).

Figura 3 - TRC por pavimento.

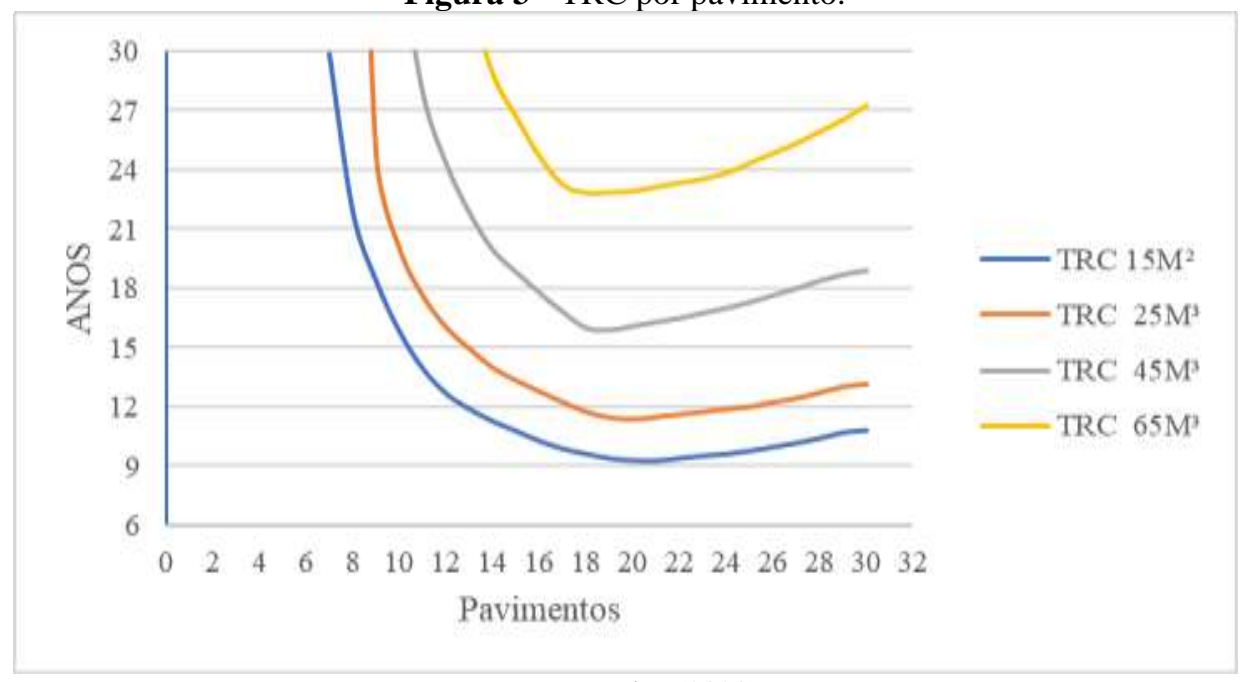

Fonte: Martins (2020).

É notável que os maiores valores do VPL e B/C são para o reservatório de menor volume. Isso é justificável pelo baixo custo desse reservatório em relação aos demais e pelos altos índices da porcentagem de aproveitamento da água captada.

Pode ser observado que para o reservatório de $15 \mathrm{~m}^{3} \mathrm{o}$ valor do $\mathrm{B} / \mathrm{C}$ é maior que 1 a partir do pavimento 7 , já para o reservatório de $65 \mathrm{~m}^{3}$, o de maior volume testado, apenas a partir de 14 pavimentos encontrou-se /C acima de 1 . No panorama geral, 79,8\% dos cenários apresentam B/C maior que 1. Restringindo essa análise para o reservatório de 15m³, 92,31\% dos cenários apresentaram B/C maior que 1, em contrapartida, o reservatório de $65 \mathrm{~m}^{3}$ apresentou $65,38 \%$ dos valores do B/C maior que 1. O melhor desempenho atingido foi para o cenário de 21 pavimentos e reservatório de $15 \mathrm{~m}^{3}$, com o B/C de 1,96, VPL de $\mathrm{R} \$ 24.446,92$ e período de retorno em 9,3 anos.

Em relação ao TRC, pode ser observado na Figura 5 que, assim como o VPL e o B/C, o reservatório de $15 \mathrm{~m}^{3}$ apresentou os menores tempos de retorno. Do pavimento 17 ao 26, o TRC foi superior a 9 e inferior a 10 anos, sendo esses os melhores resultados para TRC nesse estudo. Entretanto, os pavimentos 5 e 6 não apresentaram período de retorno durante a vida útil de projeto. Já para o reservatório de $65 \mathrm{~m}^{3}$ o menor período de retorno foi de 24,6 anos, do pavimento 5 ao 12 o tempo de retorno foi superior a 30 anos e em alguns casos não apresentou TRC. Dos 104 casos observados, em 79,8\% encontrou-se período de retorno inferior a vida útil de projeto. 
Athayde Júnior et al. (2008), em estudo de residências com diferentes padrões econômicos na cidade de João Pessoa através do método Rippl, concluíram que o aproveitamento de água pluvial é viável apenas em residências de alto padrão, devido ao cenário de tarifas vigente à época, com valor presente líquido variando de $R$ \$ $1.278,17$ a $R$ \$2.254,00, razão benefício/custo variando de 1,30 a 1,47, e período de retorno variando de 8,17 a 10,19 anos.

No estudo de Moura et al. (2018), por meio da análise de viabilidade econômica realizada para implantação dos reservatórios de captação de água pluvial em uma edificação multifamiliar, pôde-se concluir que a implantação de um sistema em um edifício deste porte se mostrou tecnicamente e economicamente viável para a obra em questão. O sistema dimensionado pôde atender a quase toda a demanda requisitada para rega de jardins, todos os dias do mês, trazendo benefícios ambientais e financeiros futuros para os moradores deste empreendimento, além de valorização do imóvel e da construtora como um todo.

Marques et al. (2014) demonstraram que o aproveitamento de águas pluviais para o Campus Campina Grande do IFPB é economicamente viável comparando-se os custos referentes à implantação e manutenção do sistema com a economia de água comprada. A análise econômica do investimento para um reservatório de $787 \mathrm{~m}^{3}$ num período de 30 anos de vida útil do sistema, com taxa de juros compostos de $8.5 \%$ ao ano, demonstrou um benefício econômico anual em torno de $\mathrm{R} \$$ 39.609,70 comparado ao volume de água que deixaria de ser comprada, resultando numa economia de $\mathrm{R} \$ 45.5148,90$ durante o período de vida útil do sistema e obtendo-se a relação benefício/custo $=2.52$, com VPL $=\mathrm{R} \$ 274.701,45$ e período de retorno de cerca de 9 anos e 10 meses.

Assim como no estudo de Marques et al. (2014), os sistemas de captação de água da chuva dos estudos de Morais (2017), Mello et al. (2014) e Pêgo e Erthal Júnior (2012) também se mostraram economicamente viáveis para a implantação em instituições de ensino.

Maltzahn et al. (2020) realizaram o estudo no município de Porto alegre-RS. Foram dois estudos de caso, sendo o primeiro em uma habitação popular multifamiliar, padrão Minha Casa Minha Vida, com 5 pavimentos, 20 apartamentos e área de coberta de $186 \mathrm{~m}^{2}$. Foi adotado um reservatório de $25 \mathrm{~m}^{3}$ seguindo o dimensionamento de Rippl, para este reservatório calculou-se os custos de instalação e o VPL em um período de 30 anos. Concluiu-se que no período analisado, o VPL é negativo, ou seja, ao logo da vida útil da instalação a mesma não se paga. O segundo estudo de caso foi para uma habitação popular unifamiliar padrão Minha Casa Minha Vida, com a área de captação de $45 \mathrm{~m}^{2}$, utilizando o método de Rippl aplicou-se um reservatório de $5 \mathrm{~m}^{3}$. Como resultado obteve-se um VPL negativo em análise para um período de 30 anos. Os autores não levaram em consideração despesas com manutenção e limpeza e taxas de juros.

Um fator considerado chave que pode ser associado ao resultado alcançado por Maltzahn et al. (2020) é o baixo custo da água potável no município de Porto Alegre. Entretanto, este resultado se aplica à situação mais desfavorável, visto que a capital gaúcha pratica a menor tarifa de água do estado. Outros municípios do Rio Grande do Sul praticam tarifas de R \$ 5,61, que aproximam o investimento da viabilidade econômica, mas ainda com um período de retorno superior aos 30 anos. A tarifa de água que torna o investimento, proposto no caso de residências unifamiliares, economicamente atrativo, dentro do período analisado, é de $\mathrm{R} \$ 6,38$, sendo assim, o projeto se viabilizaria em estados como o de Goiás, que cobra valores superiores a $\mathrm{R} \$ 10,00 / \mathrm{m}^{3}$ para os serviços de distribuição de água, coleta e tratamento de esgotos (Maltzahn et al., 2020).

Conforme constatado, algumas variáveis são importantes para a viabilidade econômica dos sistemas de aproveitamento de água da chuva, como o volume da chuva, área de captação, demanda por água não potável e tarifa de água.

A demanda por água não potável está diretamente relacionada a viabilidade, uma vez que existe uma tarifa mínima de água cobrado por um volume de $10 \mathrm{~m}^{3}$. Ou seja, mesmo que o consumo de água potável seja inferior a $10 \mathrm{~m}^{3}$, não haverá redução na tarifa cobrada pelo consumo de água. Portanto, em residências em cujo consumo é inferior a este valor, a implantação de sistema de captação de água da chuva, em alguns casos, é economicamente inviável. 
Andrade et al. (2019) demonstram que a demanda por água não potável está diretamente relacionada com a viabilidade, quando, nos dois casos apresentados na Tabela 1, variando somente a demanda por água, o primeiro caso, com demanda de 752,24 mªno apresentou VPL de $\mathrm{R} \$ 53.322,80$ e período de retorno de 3,01 anos, enquanto a demanda de 140,24 $\mathrm{m}^{3} /$ ano apresentou VPL negativo.

A tarifa de água cobrada também influencia a viabilidade econômica do sistema, ao passo que, quanto mais alta a tarifa, menor o período de retorno. Essa constatação pode ser observada no estudo de Cardoso et al. (2020), em que, no caso da UFPA, que não compra água da distribuidora, a implantação do sistema se tornou inviável economicamente, ao passo que, no caso da EMUFPA, onde a tarifa de água custa $\mathrm{R} \$ 7,35$, o sistema de aproveitamento de água da chuva apresentou VPL de R\$ 17.865,31 em um período de retorno de 10 anos.

De acordo com Romano et al. (2016), o preço da tarifa tem uma correlação negativa com o consumo de água, ou seja, quanto maior a tarifa de água, menor o consumo e maior o interesse na busca de fontes alternativas de água. Dessa forma, o governo precisa fornecer apoio financeiro para promover a instalação desses sistemas em edifícios.

Para cenários de edifícios com baixo número de pavimentos, a atratividade do sistema é menor, pois a demanda solicitada é pequena em relação a oferta, assim o benefício não é viabilizado em alguns casos. Quando essa análise considera maior número pavimentos, a demanda de água se aproxima ou é maior que oferta. Como a oferta é limitada, o VPL e B/C começam a diminuir em determinado ponto, quando a demanda se torna muito maior que oferta e toda água captada é consumida no mês vigente. Nesta mesma linha de raciocínio, o TRC aumenta.

\subsection{Disposição da População}

Durante a aplicação dos formulários, buscou-se entrevistar os moradores que tivessem adquirido imóvel recentemente ou estivessem em busca, obtendo-se, assim, uma maior credibilidade nas informações registradas. A partir dos resultados das entrevistas foram realizadas diversas análises, que permitiram avaliar o nível de conhecimento da população com relação à utilização da água pluvial bem como sua aceitação para uso em residências.

Observou-se que $87,9 \%$ dos entrevistados declararam ter conhecimento da utilização de águas pluviais em residências, evidenciando que tal alternativa já é do conhecimento da maioria da população pessoense adulta. Do percentual que tem conhecimento do assunto, 82,8\% informaram que não utiliza sistema de captação e aproveitamento das águas pluviais, evidenciando que, apesar da maioria da população ter conhecimento da ideia, ela ainda não é muito utilizada.

Após a análise de conhecimento e utilização do sistema, foi levantado o interesse da população em adquirir um imóvel que dispusesse de um sistema de captação e aproveitamento de águas pluviais, e o resultado foi bastante positivo, visto que 96,6\% dos entrevistados possuíam interesse em adquirir uma residência com sistema de aproveitamento de água da chuva.

Para os que possuíam interesse no sistema, foi analisado a disposição financeira para investir a mais no imóvel, a maioria $(57,1 \%)$ pretendia pagar de 0,1 à $2 \%$ a mais no imóvel, 26,8\% pagariam de 2,1 a $4 \%, 10,7 \%$ pagariam de 4,1 a $6 \%$, $1,8 \%$ pagariam de 6,1 a $8 \%$ e 3,6\% dos entrevistados pagariam de 8,1 a $10 \%$ a mais no imóvel (Figura 6). 
Figura 6 - Disposição dos entrevistados em pagar a mais por um imóvel com sistema de aproveitamento de água da chuva.

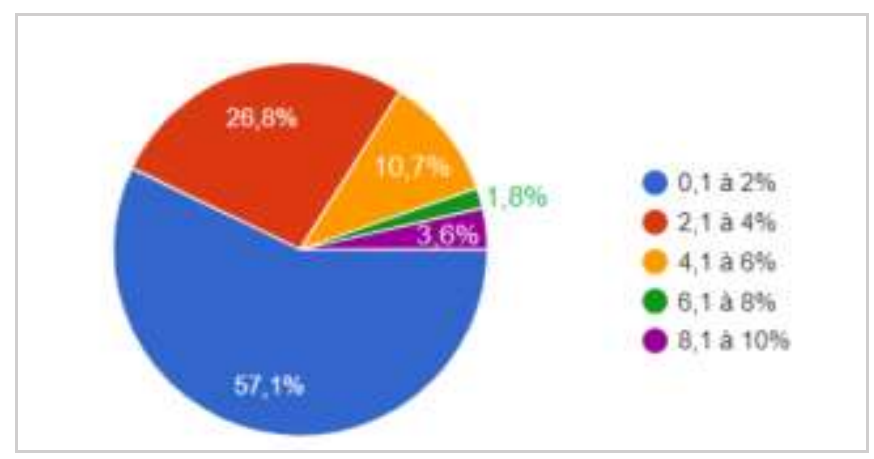

Fontes: Menezes (2019).

Este resultado demonstra que o sistema de captação e uso de água da chuva deve impactar o mínimo possível no custo total da obra, para que seja atrativo aos construtores.

\section{Considerações Finais}

Em relação ao número de pavimentos, o sistema mostrou-se economicamente viável a partir de 7 pavimentos, a depender do volume do reservatório adotado. Observou-se que a atratividade econômica aumenta até cerca de 18 a 21 pavimentos, também a depender do volume do reservatório considerado.

Em relação ao volume do reservatório, o de $15 \mathrm{~m}^{3}$ mostrou-se mais atrativo que os demais volumes $\left(25,45\right.$ e $\left.65 \mathrm{~m}^{3}\right)$, para o qual, 92,31\% dos cenários apresentaram viabilidade econômica, sendo essa a melhor opção de armazenamento entre as demais, apresentando baixo custo, bom aproveitamento da água captada e um melhor equilíbrio entre demanda, área de captação e oferta pluviométrica, quando realizado o balanço volumétrico. O melhor desempenho atingido foi para o cenário de 21 pavimentos e reservatório de $15 \mathrm{~m}^{3}$, com o B/C de 1,96, VPL de $\mathrm{R} \$ 24.446,92$ e período de retorno em 9,3 anos.

Os resultados demonstraram que dos 104 cenários observados, 79,8\% apresentaram viabilidade econômica. Cabe ressaltar ainda, que este percentual é bastante sensível à tarifa de água, bem como à distribuição sazonal das chuvas.

Por fim, a partir da aplicação dos formulários, foi possível determinar a disposição da população da cidade de João Pessoa em pagar a mais por um sistema de captação e aproveitamento de água da chuva, revelando que 83,9\% da população tem interesse em pagar, pelo menos entre $0,1 \%$ à $4 \%$, a mais sobre o valor pago no imóvel. Isso mostra que uma grande parte da população já apresenta algum tipo de consciência e/ou interesse por sistemas sustentáveis.

Como pesquisas futuras, sugere-se analisar a viabilidade econômica da alternativa para outros cenários de tarifa de água que não o praticado em João Pessoa.

\section{Referências}

Agência Nacional de Águas. (2019). Águas no mundo.

Andrade, A. E. F. (2018). Estudo da viabilidade econômica para sistema de aproveitamento de águas de chuva na sede da CBTU em João Pessoa. Trabalho de Conclusão de Curso (Bacharel em Engenharia Civil). Universidade Federal da Paraíba, João Pessoa - PB.

Andrade, A. E. F., Athayde Júnior, G. B., Carneiro, M. A. \& Ferraz, E. K. V. (2019). Estudo da viabilidade econômica para sistema de aproveitamento de águas de chuva na sede da companhia brasileira de trens urbanos em João Pessoa/PB. In: II Simpósio Nacional de Gestão e Engenharia Urbana: SINGEURB, 2019, São Paulo. Anais...: ANTAC.

Athayde Júnior, G. B., Dias, I. C. S. \& Gadelha, C. L. M. (2008). Viabilidade Econômica e Aceitação Social do Aproveitamento de Águas Pluviais em Residências na Cidade de João Pessoa. Ambiente Construído. 8(2), 85-98.

Brasil. (2017). Lei $\mathrm{n}^{\circ}$ 13.501, de 30 de outubro de, 2017. Altera o art. 2 da Lei $\mathrm{n}^{\circ}$ 9.433, de 8 de janeiro de 1997, que estabelece a Política Nacional de Recursos Hídricos, para incluir o uso da água da chuva como um de seus objetivos. 
Cardoso, R. N. C., Blanco, C. J. C. \& Duarte, J. M. (2020). Technical and financial feasibility of rainwater harvesting systems in public buildings in Amazon, Brazil. Journal of Cleaner Production. 260(121054), 1-13.

Domènech, L. \& Saurí, D. (2011). A comparative appraisal of the use of rainwater harvesting in single and multi-family buildings of the Metropolitan Area of Barcelona (Spain): Social experience, drinking water savings and economic costs. Journal of Cleaner Production. 19(6-7), 598-608.

Ghimire, S. R., Johnston, J. M., Garland, J., Edelen, A., Ma, X. C. \& Jahne, M. (2019). Life cycle assessment of a rainwater harvesting system compared with an AC condensate harvesting system. Resour. Conserv. Recycl. 146, 536-548.

Gil, A. C. (2007). Métodos e técnicas de pesquisa social. (5a ed.), Atlas.

Hajani, E. \& Rahman, A. (2014). Rainwater utilization from roof catchments in arid regions: a case study for Australia. Journal of Arid Environments. 111, $35-41$.

Jimenez Cisneros, B. E., Oki, T., Arnell, N. W., Benito, G., Cogley, J. G., D€Oll, P., Jiang, T. \& Mwakalila, S. S. (2014). Freshwater resources. Intergovernmental panel on climate change (IPCC), climate change 2014: impacts, adaptation, and vulnerability. In: Contribution of Working Group II to the Fifth Assessment Report of the IPCC. Cambridge University Press, Cambridge/New York, UK/USA, 229-269.

Kuchinski, V. \& Gastandini, M. C. C. (2017). Viabilidade técnica e econômica do aproveitamento das águas de chuva e cinza para consumo não potável em edifício residencial de Santa Maria (RS). Revista DAE. 207(1677), 5-19.

Maia, A. G., Santos, A. L. \& Oliveira Filho, P. C. (2011). Avaliação da economia de água potável com a implantação de um sistema de aproveitamento de água de chuva: estudo de caso no município de Irati, Paraná. Ambiência Guarapuava. 7(1), 51 - 63.

Maltzahn, M. A. (2020). Proposta de sistema de aproveitamento de água da chuva para habitação popular: avaliação econômica de projeto. Trabalho de Conclusão de Curso (Bacharel em Engenharia Civil). Universidade Federal do Rio Grande do Sul.

Marques, C. M., Athayde Junior, G. B. \& Luna, Y. H. M. (2014). Proposição de um Sistema de Água de Chuva para um Instituto de Ensino na Região Nordeste do Brasil: Estudo da Viabilidade Econômica. Revista AIDIS. 7(3), 259-271.

Martins, B., E., S. (2020). Análise da viabilidade econômica do aproveitamento de água de chuva para edificações verticais do tipo residencial na cidade de João Pessoa-PB. Trabalho de Conclusão de Curso (Bacharel em Engenharia Civil). Universidade Federal da Paraíba, João Pessoa-PB.

Matos, C., Teixeira, C. A., Duarte, A. A. L. S. \& Bentes, I. (2013). Domestic water uses: characterization of daily cycles in the north region of Portugal. Sci. Total Environ. 458, 444-450.

Mello, M., Pertel, M. \& Souza, F. P. (2014). Análise de viabilidade econômica: um estudo de aproveitamento da água de chuva no Instituto Educacional Paulo de Tarso. Persp. online: exatas \& eng. 4(8), 31-50.

Menezes, L. K. M. (2019). Pesquisa de intenção acerca da disposição financeira na aquisição de imóveis residenciais dispondo de sistemas de aproveitamento de água de chuva em João Pessoa. Trabalho de Conclusão de Curso (Bacharel em Engenharia Civil). Universidade Federal da Paraíba, João Pessoa - PB

Mohammed, T. A., Noor, M. J. M. M. \& Ghazali, A. H. (2007). Study on potential uses of rainwater harvesting in urban areas. In: Proceedings of the Colloquium on Rainwater Utilization. Ministry of Natural Resources and National Hydraulic Research Institute of Malaysia (NAHRIM), Putrajaya, Malaysia, $1-15$

Morais, J. W. A. (2017). Viabilidade técnica/econômica no aproveitamento de água de chuva para fins não potáveis em uma instituição de ensino do Amazonas. Dissertação (Mestrado em Engenharia de Produção). Universidade Federal do Amazonas, Manaus-AM.

Moura, M. R. F., Silva, S. R. \& Barros, E. X. R. (2018). Análise de implantação de um sistema de aproveitamento de água pluvial em um empreendimento residencial na cidade de Recife-PE. Tecno-lógica. 22(1), 66-72.

Pacheco, P. R. C., Gomez, Y. D., Oliveira, I. Z. \& Teixeira, L. C. G. (2017). A view of the legislative scenario for Rainwater harvesting in Brazil. J. Clean. Prod. 141, 290-294.

Pêgo, C. S. \& Erthal Junior, M. (2012). Dimensionamento e viabilidade econômica da coleta e uso de águas pluviais no município de Campos dos Goytacazes. Perspectivas Online. 2(3), 41-53.

Richardson, R. J. (2017). Pesquisa social: métodos e técnicas. (4a ed.), Atlas.

Romano, G., Salvati, N. \& Guerrini, A. (2016). An empirical analysis of the determinants of water demand in Italy. J. Clean. Prod. 130, 74-81.

Salla, M. R., Lopes, G. B., Pereira, C. E., Neto, M., Da Costa, J. \& Pinheiro, A. M. (2013). Viabilidade técnica de implantação de sistema de aproveitamento de água pluvial para fins não potáveis em universidade. Ambiente Constr. 13(2), 167-181.

Silva, C. M., Sousa, V. \& Carvalho, N. V. (2015). Evaluation of rainwater harvesting in Portugal: application to single-family residences. Resource Conservation Recycling. 94, 21-34.

Sistema Nacional de Informações Sobre Saneamento. (2018). Diagnóstico dos Serviços de Água e Esgoto 2018. Ministério do Desenvolvimento Regional.

Thomas, R. B., Kirisits, M. J., Lye, D. J. \& Kinney, K. A. (2014). Rainwater harvesting in the United States: a survey of common system practices. J. Clean. Prod. 75, 166-173.

Ward, S., Barr, S., Butler, D. \& Memon, F. A. (2012). Rainwater harvesting in the UK: socio-technical theory and practice. Technol. Forecast. Soc. Change. 79(7), 1354-1361. 
Research, Society and Development, v. 10, n. 8, e49010817655, 2021

(CC BY 4.0) | ISSN 2525-3409 | DOI: http://dx.doi.org/10.33448/rsd-v10i8.17655

World Health Organization. (2019). Progress on household drinking water, sanitation and hygiene 2000-2017. Special focus on inequalities. New York: United Nations Children's Fund (UNICEF) and World Health Organization.

World Water Assessment Programme. (2015). The United Nations World Water Development Report (WWDR 2015): Water for a Sustainable World. Paris, UNESCO.

Zhang, X. \& Hu, M. (2014). Effectiveness of rainwater harvesting in runoff volume reduction in a planned industrial park, China. Water Resour. Manage. 28, $671-682$. 